\title{
The Negotiator and the Bomber: an interactive analysis of the critical role of active listening in crisis negotiations
}

\author{
Name: $\quad$ Dr. Terry Royce \\ Position: Director, Graduate Program \\ Affiliation: Teachers College, Columbia University (Japan), \\ Mitsui Seimei Bldg. 4F. 2-21-2 Misaki-cho, \\ Chiyoda-ku, Tokyo, JAPAN 101-0061
}

Phone: $\quad$ 81)-3-3221-9771

Fax: $\quad(81)-3-3221-9773$

Email: $\quad$ troyce@tc-japan.edu

Acknowledgment:

I wish to thank Detective Inspector John O’Reilly, former Metropolitan Team Leader of the NSW Police Service Negotiation Team, for his cooperation, assistance and advice in the preparation of this paper, and the invaluable data upon which the analyses are based. 


\begin{abstract}
This paper extends Hammer and Rogan's (1997) communication-based, interactive model of crisis negotiation by examining the role of active listening by a Police negotiator in New South Wales, Australia in the serving of a "high-risk warrant" on an armed and dangerous perpetrator who is expected to resist. Through an analysis of the interaction between the perpetrator and the negotiator, this paper demonstrates that the use of active listening in the early stages of the negotiation are critical factors in the resolution of this crisis.
\end{abstract}

\title{
INTRODUCTION
}

Currently, many police forces around the world recognize that negotiation, as opposed to a tactical response, is "one of the most important tools available in law enforcement to peacefully resolve crisis events” (Noesner 1999: 6). This has not always been the case. For example, the FBI has had, since the establishment of its Behavioral Science Unit (BSU) in the early 1970s and more recently its Critical Incident Response Group (CIRG), a series of intramural disagreements about the ways that it should respond to a crisis. These disagreements have been played out in siege incidents such as those by the right-wing militants at Ruby Ridge, Idaho, and the Branch Davidian Sect in Waco, Texas (Franks 1996: 27-8). Clinton van Zandt, one of the chief FBI negotiators in both these incidents at the time, argued for the use of persuasion over force, but had been over-ruled by the traditional segments of the FBI hierarchy, which favored more tactical solutions to the stand-offs. In the aftermath, it was alleged that the negotiation teams were in fact stymied by the actions of the tactical teams (30), and that the resultant high loss of life could have been avoided if the on-scene decision-makers had more of an understanding of negotiators' skills and methods (Noesner 1999: 6).

The lengthy reviews of these incidents lead to the establishment by the FBI of a block of instruction for potential crisis managers aimed at providing them with an understanding of the important principles and concepts deemed necessary to manage the negotiation process during a crisis event (7). The FBI currently classifies crisis incidents into two main types. The first is a hostage situation, where the perpetrator holds another person or persons captive in order to have some substantive demands fulfilled (money, freedom, political change etc), where the hostages are used as leverage, and where the primary goal of the hostage taker is not to harm the hostages. The second type is a nonhostage situation, where "individuals act in an emotional, senseless, and often self-destructive way” (8). The subjects in this situation are clearly 
in the midst of a personal crisis where they have failed to deal effectively with various life stressors, and have responded with or are motivated by strong emotions associated with resentment, extreme anger, frustration, depression etc. These kinds of perpetrators have no clear or substantive goals, and express their frustrations by undertaking such actions as barricading themselves and sometimes holding others against their will - in this case the person held is technically not a hostage but a victim who is restrained in order to express anger at him or her, or at events (8).

The negotiation processes involved in both these crisis situations necessarily vary in terms of the law enforcement strategies employed (see summary in Noesner 1999: 9), but both are characterized by a recommendation to apply active listening to resolve the crisis. In the interactive CD-ROM The Incident, which was developed in cooperation with the FBI for negotiator training, active listening is described as "the backbone of negotiation" (Emery 2002; Will Interactive 2004), and given the importance of this skill in police training (McMains \& Mullins 2001; National Council of Negotiation Associations [NCNA] 2001; Crisis Negotiation 2004; etc.), and for the management of actual crisis incidents (Wind 1995; Noesner \& Webster 1997; Noesner 1999; Lanceley 1999; etc.), this paper will focus on the use of active listening by a negotiator for the New South Wales (NSW) Police Service, Australia, in the serving of a "high-risk warrant" on a perpetrator who is known to be armed, is expected to resist, and has demonstrated that he is a serious danger to other people (McMains \& Mullins 2001: 39-40).

The perpetrator (hereafter referred to as 'the Bomber') lives on his own farm in rural NSW and was alleged to be regularly entering a nearby town carrying loaded weapons and wearing a live body-bomb, ostensibly for his own protection against perceived threats. The crisis situation analyzed here fits into the "nonhostage situation" classification, and as such is a critical incident involving an expressive subject (Noesner \& Webster 1997). There is however one important difference which varies from the situation which would typically face a negotiator who is called out for a crisis incident - this is the access to and use of advance intelligence, gathered by both the tactical, bomb disposal, and negotiator teams and then used to effect in the application of active listening in the actual negotiation. It is proposed that one of the main reasons why this crisis ends in a successful containment and arrest rather than escalation and subsequent loss of life is that the use of active listening in the early 
stages, supported by the use of contextual and background intelligence on the Bomber by the negotiator, sets the stage for resolving this crisis.

\section{THEORETICAL BACKGROUND}

\section{Models of Crisis Negotiation}

Hammer \& Rogan (1997), in their review of negotiation models in crisis situations, posit that since the 1970s law enforcement professionals have increasingly relied upon negotiation as the most appropriate alternative to the use of tactical assault to resolve terrorist, hostage, barricade [siege] and suicide situations. They suggest that an initial classification of negotiation dynamics by early scholars in this area has lead to the use of two main approaches to crisis negotiation. These have been categorized as the instrumental approach and expressive acts approach, a categorization that has basically served as a "general template through which negotiators determine the type of crisis negotiation situation they are facing and the subsequent strategies employed for obtaining a resolution” (9).

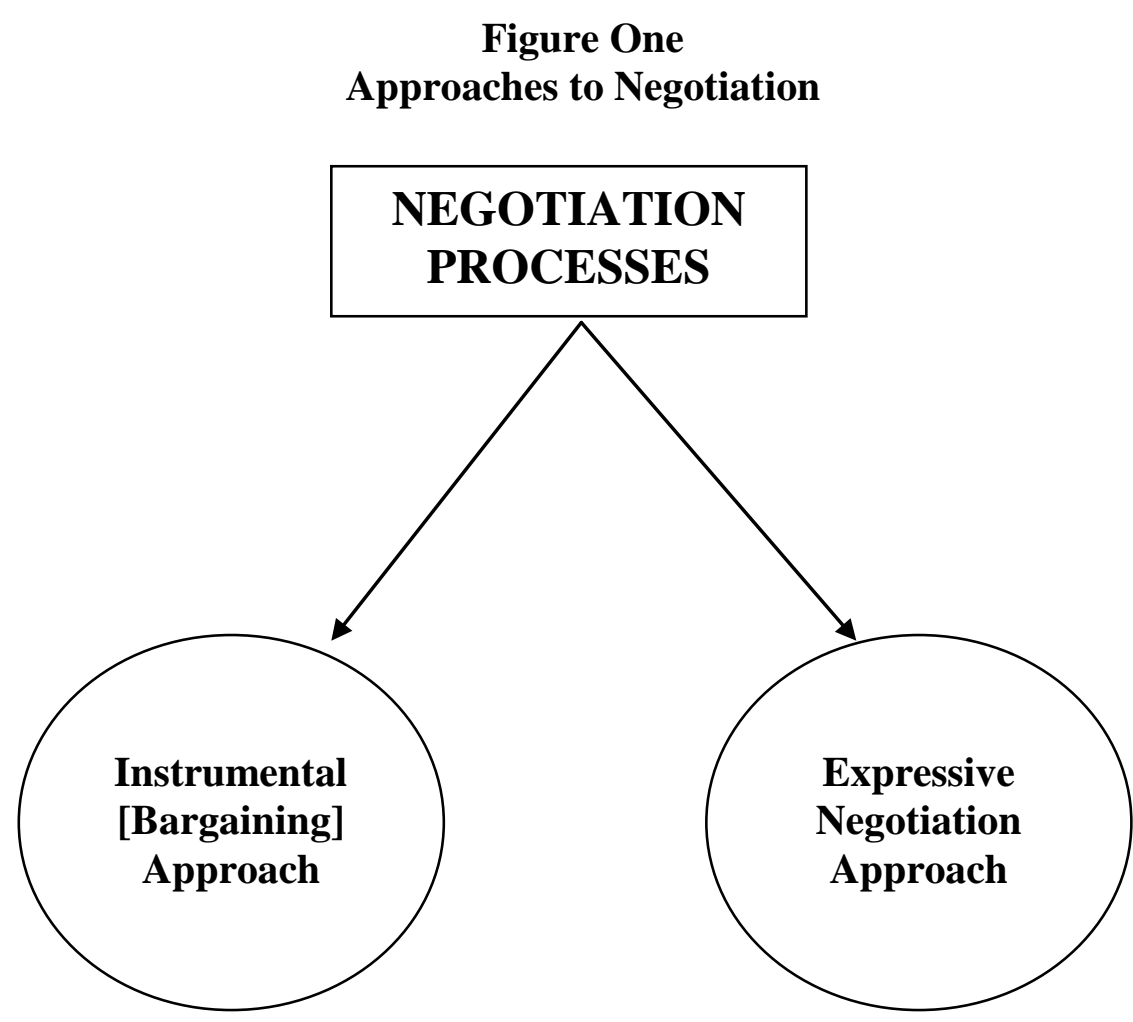

The first of these approaches, the Instrumental or bargaining approach model, derives from social exchange theory and "conceptualizes crisis negotiations in terms of instrumental issues present during negotiation". These relate to "those situationally related, substantive, objective wants or demands of each party......[whereby] 
negotiation is viewed in terms of efforts by each party to dictate or clarify the terms of an exchange or distribution of resources” (10). Further, social exchange theory as applied to negotiation "posits a rational actor model of negotiation which characterizes effective negotiation as the result of rational discourse between contending parties [i.e. where each party focuses on instrumental, substantive issues and makes logical cost/benefit choices]” (10).

The orientation of the behaviors of the subjects or the negotiators in this "bargaining" approach is thus towards some kind of substantive instrumental outcome [as opposed to non-substantive], and it essentially views negotiation as "agreementmaking through bargaining or problem-solving, typically via quid pro quo” (11). The Instrumental negotiation framework is also viewed by many as a powerful model which has extensive applications in other contexts such as labor/management disputes, seller/buyer interactions etc, but there are problems with this approach in the area of crisis negotiations, in that the situations with which law enforcement officers are often faced are those where the assumption of rationality, where the willingness to bargain, and where the focus is expected to remain on instrumental issues is often not possible to maintain (11). For example, if discussions break down and a perpetrator refuses to talk anymore, a crisis negotiator cannot simply adjourn the interaction until a later time, as can be done in a business meeting (10).

A further point is that in crisis negotiation situations subjective factors frequently play a crucial role. These very often involve high levels of anxiety, emotion, apprehension, and uncertainty for both parties, and it is often the fact that it is a failure by the perpetrator to cope emotionally in some way to various life stressors which has actually led to a need for intervention by police negotiators (10-11). Additionally, surveys of negotiation team leaders in the US have shown for example that many incidents actually involve critical aspects of relationship and face issues, in combination with the various elements of instrumental behavior (12). These subjective factors support the view that objective bargaining should not be assumed to be the most appropriate approach to characterize negotiation processes.

Consequently the other major model, the Expressive negotiation approach, has also been proposed as a recommended model for the resolution of crisis situations. In this approach, which has its derivation in psychotherapy (see Schlossberg 1979, as well as Fuselier 1999, for more recent views on negotiation and the Stockholm Syndrome), it is presumed that "the nature and quality of interpersonal relationships 
plays a large role in resolving conflict” (Hammer \& Rogan 1997: 12). The Expressive negotiation approach of course contrasts with the instrumental bargaining approach in that it views emotion and relationship variables as the central elements. Thus relationship development in terms of developing rapport and building trust are viewed as crucial to resolving crisis incidents, and it is often recommended that the training of negotiators within the expressive framework should give emphasis to [active] "listening, paraphrasing, self-disclosure, open-ended questioning, and specific skills for reducing the perpetrator's anxiety level” (13).

Hammer \& Rogan (14), further posit that while the instrumental and expressive acts approaches have been clearly of great benefit to developing an understanding of negotiation dynamics, these approaches have been mainly utilized for assessing perpetrator behavior only, as well as his or her emotional and mental state. They argue that what is more appropriate is a communication-based or interactive framework, where "crisis negotiation [should be examined] from a communication or interaction perspective, focusing on both perpetrator and negotiator behavior as manifest in verbal messages” (14). This interactive perspective takes into account the fact that the situation is a developing one that is actually created by the interactants as they exchange messages with each other.

Hammer \& Rogan outline their communication approach by suggesting that all communication, in line with basic communication theory, has both a content and relational dimension. The former relates to the instrumental focus of communication, while the latter refers to its expressive features (which is further broken down into relational and identity information). They further posit that "parties to conflict interaction pursue three functional interactional concerns which impact on conflict escalation/de-escalation - these are instrumental, relational, and identity or face goals” (14-15). Their aim is thus to develop a model of negotiation that takes into account the already-mentioned instrumental and expressive aspects of negotiation processes, and to interpret these in a negotiation interactively as the negotiation unfolds.

This view accords with current understandings on spoken grammar in functional linguistic theories (Halliday 1994) and models of spoken discourse analysis such as conversational analysis (Psathis 1995). When two (or more) people interact they not only deal with certain subject matter, topics or experiences relevant to the context in which they are situated, they also establish relationships between themselves: between 
the person who is speaking at a particular moment, and between the person who will probably speak next. To establish these relationships we take turns, and in those turns we take on different speech roles to exchange meanings (and therefore positions of power). The basic speech roles are Giving and Demanding (Halliday 1994:69) and these generate other speech function pairings such as statement-acknowledgement, question-answer, command-compliance, offer-acceptance etc. Depending on the role taken up by a speaker, information is bandied back and forth between the interlocutors, and is adjusted in terms of probability or usuality by the use of the modality resources in English (might, possibly, could, frequently, rarely, etc.). As speakers take up the initial speech roles, the dialogic exchange moves through what can be characterized as moves or phases, with a shifting of speech roles and positions of power taken up (such as initiator, responder etc). Spoken interaction thus involves the dynamic process of building some kind of relationship between the speakers, and it is in this latter area of relationship-building to which active listening is most closely related.

\section{Active Listening}

As already mentioned, one of the purposes of this paper is to also analyze the interactive linguistic choices made by a NSW Police negotiator in his application of one of the important and recommended skills in the expressive model - the use of active listening. Much of the literature on crisis negotiation suggests that one of the most important skills for a police negotiator to be able to settle a crisis is to have considerable expertise in 'discussing or conferring", and that integral to this is the ability to hear what the other person is saying (McMains \& Mullins 2001: 33-34). In other words, the negotiator needs to be proficient at active listening (Noesner \& Webster 1997; Noesner 1999; Lanceley 1999; et. al.).

Active listening as an interpersonal skill is taught and utilized across a wide range of communicational contexts. Its specific definition varies based on the ways that it is approached in these various contexts, but generally it deals with listening constructively, with a focus on an understanding of the other person's feelings, or an empathizing (Cambria et. al. 2002: 339) Active listening is important in the area of dispute/conflict resolution and mediation (Potter 1995) and is understood to be "a way of listening and responding to another person that improves mutual understanding. Often when people talk to each other, they don’t listen attentively ... [and] ... rather 
than paying attention, they focus on how they can respond to win the argument” (Active Listening: International Online Training Program On Intractable Conflict 1998). It is also prominent in contexts for marital, religious, self-help, parenting and even educational counseling or advice (Landsberger 2003; Rosenthal 2003), or in journalism, sales and management (Romano 2002), and suicide prevention (Listening Skills: A powerful key to successful negotiating 2000). It is also commonly referred to or synonymized as “empathetic listening” which according to Pickering (1986) can be interpreted in terms of the desire to be other-directed and non-defensive, to imagine the roles, perspectives, or experiences of the person(s) being addressed, and to listen to understand them rather than attempting to achieve either agreement or produce some kind of change in them.

Active listening for crisis negotiators however, is generally defined as "the ability to see a circumstance from another's perspective and to let the other person know that the negotiator understands his [or her] perspective” (Lanceley 1999: 17). Noesner \& Webster (1997: 16-18) use both semantic and verbal skills labels in their often-quoted list in the FBI Law Enforcement Bulletin to describe the necessary active listening skills for a negotiator. These are:

- Minimal Encouragements: the negotiator uses verbal responses or replies to indicate that he/she is listening: $(O K$, I see...).These are also referred to by discourse analysts as ‘back-channeling’.

- $\quad$ Paraphrasing: the negotiator repeats the perpetrator's message back in his own words to convey understanding, and to show that he is listening.

- Emotion labeling: the negotiator labels or names the perpetrator's feelings to gain some insight into his/her attitudes and behavior.

- Mirroring: the negotiator repeats the last words/ phrases or main idea provided by the perpetrator so as to build rapport.

- Open-ended questions: the negotiator asks questions which require more than a yes/no answer to get the perpetrator to communicate, and makes an effort to avoid 'why' questions, which may suggest a sense of interrogation.

- 'I' messages: the negotiator expresses his feelings about the perpetrator's actions etc. so he seems like a real person to the perpetrator (I feel frustrated that ....). 
- Effective pauses: the negotiator uses silence to encourage the subject to talk and to help to calm him/her down.

The active listening skill is used therefore to "thoughtfully communicate with the hostage taker, defuse the conflict, and work toward establishing a level of rapport that allows them to explore problem-solving options and progress to a nonviolent resolution” (Noesner 1999: 8). As a strategy for lowering subjects' emotions, defusing anger, and returning the subjects to more rational thinking, it is also used for "building trust and rapport by demonstrating understanding of and concern for subjects" and it is recommended that "negotiators should specifically demonstrate through word and expression that they understand the issues that are important to or bother subjects [their stories] and how subjects respond to those issues [their feelings]" (8). The establishment of a trusting relationship then opens the way for the perpetrator to be introduced to nonviolent problem-solving alternatives which can enhance compliance and to bring about a successful, non-tactical resolution to a crisis.

Subsequent discussions of the characteristics of active listening for crisis negotiation are provided by Lanceley (1999: 20-24) and McMains \& Mullins (2001: 85-90), but these are largely reformulations of the work of Noesner \& Webster (1997) and Noesner (1999).

\section{Active Listening and the Stages of a Crisis Incident}

Active listening is not only recommended as an important and necessary skill for negotiators to use in all types of crisis incidents (Noesner 1999: 9), it is also a skill which should be used in the critical first phases of a crisis incident (McMains \& Mullins 2001: 69). As McMains \& Mullins (68-76) suggest, the stages of a crisis can be characterized as going through four distinct stages: (1) Pre-crisis, or the period where those involved in a potential crisis go about their normal daily activities, where both the negotiators and perpetrators live their respective lives as usual. (2) Crisis/Defusing, or the period where the usual has been interrupted and something triggers intense emotional excitation, the sense of unpredictability and uncertainty increases, and a subject chooses a course of action which leads to police involvement or attempts by authorities to defuse the situation. (3) Accommodation/Negotiation, or the phase where the subject involved is beginning to be open to suggestions, experiences less emotional excitation, is starting to use rational thinking, and starts to look at the problem from a different angles. (4) Resolution/Surrender, or the stage 
where the subject can see an answer to the problem, can see a clear path to a solution, tries new ideas, and move towards the conclusion of the incident.

While McMains \& Mullins acknowledge that there are other views or interpretations of the stages a crisis may go through, they do emphasize that a crisis should be viewed as a process, with "predictable stages through which people move [and that] each stage has different issues with which negotiators must deal and requires different skills that are valuable in dealing with the issues of that particular stage” (68). This aligns with the process-oriented, interactive approach taken by Hammer \& Rogan, as well as with the functional linguistic views already mentioned. For McMains \& Mullins, it is at the Crisis/Defusing stage where the role and use of active listening is specified, though they do list other active listening techniques such as open-ended questions and ' $\mathrm{I}$ ' messages, as being important in the Adaptation/Negotiation stage (69).

\section{METHODOLOGY}

The data which is the subject of this analysis of active listening was obtained from the personal tape recordings by the NSW Police negotiator involved in this crisis incident, Detective Inspector John O’Reilly, then Metropolitan Team Leader of the NSW Police Service Negotiation Team of the NSW Police Service. Additional supportive data sources were two video tapes related to the incident - one a surveillance video of the property and the bomber by the tactical team, detailing the subject's perimeter defences and habitual personal actions, the other a video with audio of the entire incident from containment to arrest. Important background and contextual information was obtained from the negotiator's personal tape recordings of an interview the negotiation team and bomb squad held with an informant, as well as informal interviews and correspondence with the negotiator, where both general and specific information relating to the incident were obtained.

The tape-recorded text was transcribed and the exchange between the Bomber and O’Reilly has been analyzed in terms of:

1. The Pre-incident context of this text: this will involve a discussion of important background details on: the gathering of background intelligence on the Bomber prior to the crisis, the approach O’Reilly took for this negotiation, and details about the tactical setup. 
2. The stages and opening moves of the 'Bomber' text: this is an analysis of how the Bomber is constrained and the situation set up so a negotiation can be initiated.

3. The places where active listening is used to establish rapport and to defuse the crisis: this involves an analysis of where and why the negotiator uses the active listening skills outlined by Noesner \& Webster (1997), and the effect on the interaction as it develops. It also includes and analysis of where other kinds of interactional devices or skills are used to establish rapport and to defuse the crisis, as well as where active listening skills are not or minimally used.

\section{RESULTS}

\section{The Pre-Incident Context}

The are a number of important factors regarding this crisis incident which impinge upon its interactive interpretation. One of them is the fact that one of the interactants (O’Reilly) has access to a great deal of prior intelligence on the other interactant (the Bomber). This was provided via in a formal interview O'Reilly and members of the tactical/bomb disposal teams held with an informant who was well aware of the bomber's personality, attitudes and behaviors. The details of this interview, which have been derived from the negotiator's own personal recordings of the interview and which reveal a rather disquieting picture of a very disturbed person, are summarized in Table One:

Table One

Informant interview results

\begin{tabular}{|c|l|}
\hline Personality traits & $\begin{array}{l}\text { Secretive, explosive temper. Paranoia - feels protected and in command when } \\
\text { wearing body-bomb in town - always wears it in town - feels it is better } \\
\text { protection in town than just handguns. Admires 'Rambo'. Limited conversational } \\
\text { abilities. Likes to feel that he is in control or has power. }\end{array}$ \\
\hline Belief systems & $\begin{array}{l}\text { No religious affiliations or beliefs in organized religion. Machines come before } \\
\text { people. His pets come before people. Human life has no value. }\end{array}$ \\
\hline Interests and Skills & $\begin{array}{l}\text { Mechanical aptitude and has respect for machines. Pilots licence. Significant } \\
\text { knowledge of and background with weapons. Able to build own firearms/cannon } \\
\text { and to construct a pressure-switched bomb. Strong interest in Thailand where he } \\
\text { feels he can do anything he wants [money and prostitution]. }\end{array}$ \\
\hline Family relations & $\begin{array}{l}\text { Estranged - did not attend mother's funeral. No contact with father. Other family } \\
\text { members seen very occasionally. His guns and dogs come before family. }\end{array}$ \\
\hline Reaction to & $\begin{array}{l}\text { Government are 'thugs' manipulate everyone (telephones, banks, TV, police etc). } \\
\text { Hates local council - they should be shot. No trust in doctors - self medicates. }\end{array}$ \\
\hline
\end{tabular}




\begin{tabular}{|c|l|}
\hline $\begin{array}{c}\text { Feelings Towards } \\
\text { Others }\end{array}$ & $\begin{array}{l}\text { Weapons are more valuable than people. Misogynist. Humans are 'domestics', } \\
\text { 'two legs' or 'functionoids'. The local townspeople should be shot and used for } \\
\text { fertilizer. No friends except 'old Nazi' in Thailand. }\end{array}$ \\
\hline $\begin{array}{c}\text { Living } \\
\text { circumstances }\end{array}$ & $\begin{array}{l}\text { Lives in caravan on own property. Largely self- sufficient existence - buys } \\
\text { supplies in town occasionally. Caravan is booby-trapped when he is away. Has } \\
\text { made land mines ready to plant on property away from access track. }\end{array}$ \\
\hline Possessions & $\begin{array}{l}\text { Keeps antique pistols/guns, 1-inch cannon, stockpile of weapons and } \\
\text { ammunition. Owns and uses forge, lathe and machine tools. }\end{array}$ \\
\hline Habitual actions & $\begin{array}{l}\text { No history of actual violence. Used to wear 2 bombs and carried } 2 \text { handguns in } \\
\text { town. Now carries one more powerful body bomb and } 3 \text { handguns. Has been } \\
\text { wearing a 'hot' pressure-switched bomb to town for about } 4 \text { months. Uses } \\
\text { motorized bike to leave property along sandy access track }\end{array}$ \\
\hline
\end{tabular}

From the results of this interview one can see that the police negotiation teams must necessarily view the Bomber as a potentially very dangerous person who has very negative attitudes to society and authority. The teams are also aware of the potential danger to others, in that the Bomber has been wearing a 'hot' body bomb and carrying concealed weapons to the nearby town for at least 4 months.

Further, one can see that both interlocutors involved in the negotiation will come to the actual exchange with vastly differing assumptions and ideological backgrounds. From the negotiator's point of view, he would view himself as a member of a governmentally-approved legal and political discourse community which follows approved operational procedures and holds certain societal values about appropriate behavior. From discussions with O'Reilly (2003), the NSW Police Force negotiation policy appears to agree with what is generally considered by scholars on negotiation dynamics to be appropriate and acceptable principles. According to McMains \& Mullins the foundation for successful crisis negotiation are attitudes of caring, understanding, and patience, all three of which contribute to the ultimate success or lack of success of a negotiation. An either/or attitude, an attitude that conflicts should be settled rapidly, or that feelings are not important, runs counter to the preferred attitudes which service the relationship element in negotiations. Also, settlement comes through "discussing or conferring", so negotiations favor words and people skills over a tactical response (2001: 33-34).

Another important aspect of prior expectations in this context can be seen in the fact that the negotiation and tactical teams fully expected that this crisis would not be resolved peacefully, and would end with the bomber's death or serious injury. According to O'Reilly (2003), this expectation was based not only on the informant's information, but also the responses received from consultations with crisis negotiation 
organizations in the United Kingdom, Israel, and US, each of which apparently responded that they would most likely have to end up shooting the Bomber. As a result, the NSW negotiation and tactical teams lodged a report with the NSW Coroner prior to the actual negotiation on the expectation that the situation would very likely end in them having to shoot the Bomber. Given the potential close oversight by various government and non-governmental organizations of police action involving life-threatening action, this kind of pre-planning to ensure legal requirements was also instrumental in the careful drafting of O'Reilly's opening statement by megaphone to the Bomber (2003). As O’Reilly commented, “My opening statement was something that I drafted in an attempt to cover all the critical information that I needed to transmit to him, as concisely as possible. Pre-incident, I believed that there was a probability that I would be talking 'at him' as he attempted to leave the ambush site and return to his property, and thus cross police lines which would result in him being shot. The opening statement would, therefore, be scrutinized down to individual syllables and tonal qualities” (2003).

On the day of the incident, the site was set up for maximum protection of the police involved, due to the possibility that the body-bomb would be detonated. Basically, the Bomber was 'ambushed' on the crest of an access road which had been chosen as a result of the covert surveillance of the property and his movements in the weeks prior to the incident. One of the aspects of this ambush which the Bomber was subsequently impressed by was its technical complexity. He was boxed in by the bush to each side of the access road, with a series of protective layers. The first layer was wire strung between knee high star pickets (similar to obstacle courses where people have to step through tires). The second layer was a string of detonator cord set up at waist height, the third layer rolls of razor tape, and the fourth layer a cyclone wire fence five feet high (2003). Thus this crisis incident is not 'typical' in the sense that a perpetrator is experiencing sudden intense emotional excitation that has been triggered from without and has as a result chosen a sudden course of action which requires police involvement. In a very real sense the police, in the interests of public safety, initiated this incident.

\section{The Stages of the Crisis and the Opening Moves of the 'Bomber' Text}

The whole exchange between O'Reilly and the Bomber from initiation to arrest, lasts for around forty-seven minutes and roughly approximates McMains \& Mullins’ 
crisis stages (2001). The stage which is of concern for this paper is the Crisis/Defusing stage, which in this incident starts off with the Bomber being surprised and then contained and isolated by the perimeters set up by the tactical squad, which then sets the scene for the negotiated steps to defusing the situation. Of course, this containment does not refer only to physical containment, but also to psychological (communicational) containment (Cambria 2002: 339). In this the Bomber is compelled to talk to O'Reilly and O’Reilly only, and there would be no use of third party intermediaries (Romano 1998: 20). The reference below to the 'witches hat' or road cone which contains the police mobile phone indicates that this procedure is being followed for this incident.

The containment and isolation features involved in the stage of the crisis incident discussed here are concerned primarily with establishing legal and behavioral boundaries via a megaphone warning to stop and stay within the defined boundaries (the dirt access road). This is a pivotal point, for if the Bomber had not complied with the megaphone warning to stop and dismount, a tactical response would have been the option taken up. The ways that the Bomber is initially isolated and contained by the police so that the negotiation can commence can be seen in the sample script extracts following. The negotiator is addressing the Bomber with a pre-prepared statement via remote megaphone from the crisis response command post, with supporting officers (Officer 1 is in the command post, Officer 2 is a field observer reporting in by radio). The Bomber is on a motorized bicycle on a narrow farm access road, and has been surrounded (boxed in) by police snipers and a Saracen (armored personnel carrier).

O’Reilly: “B” You are under arrest.

Stop immediately, and stay exactly where you are, or you may be seriously injured. There are police all around you, they know that you are armed, that you are wearing a bomb. You will be safe if you stay exactly where you are, and do exactly as I ask. Stop where you are now.

Officer 1: $\quad$ He's on the side of the road mate.

O’Reilly: $\quad$ If you do as I ask, I can guarantee that you will be safe.

Officer 1: $\quad$ Still on the side of the road.

O’Reilly: $\quad$ If you attempt to move away from the spot in which you are standing, you will be approaching armed police, who will be forced to defend themselves.

Officer 1: $\quad$ He's not far from the road kill [zone] mate.

Officer 2: $\quad$ The person of interest is just sitting up on top of the hill, he's not, he's still on his pushbike.

O’Reilly: $\quad$ Walk over to the witch's hat, and pick up the phone. If you pick up the phone, I'll talk to you over the phone. If you stand at the witch's hat, you will be safe. Please pick up the phone "B". There are armed police all around you, you cannot leave that spot. You are safe while you stay there - do not leave that spot. 
[a further two minutes of these kinds of instructions follow re the Bomber's safety and more requests to pick up the phone, until he demounts his pushbike and picks up the phone].

According to O'Reilly, if the Bomber had not moved towards the police phone and picked it up, but had moved out of the designated 'kill' zone, the police snipers would have shot him and then the bomb squad would go through the laborious and dangerous task of mechanically disarming the body bomb.

Once the Bomber is contained and isolated, O'Reilly switches from the megaphone to the actual negotiation by phone, and moves further into the crisis/defusing stage of the negotiation, into what can be generally characterized as the expressive stage of the negotiation, where he attempts to establish a relationship with the Bomber in order to convince him to comply with the request to defuse/remove the bomb, and to surrender the firearms and ammunition. It is the dialogue in this section of the exchange that is the focus of this paper, where O'Reilly uses active listening to move the crisis from the crisis/defusing stage to the adaptation/negotiations stage. Once the Bomber has been convinced in this stage to start the surrender process by disrobing and disarming his weapons, the negotiation moves into the adaptation/negotiation phase, where the Bomber is beginning to be open to suggestions, experiences less emotional excitation, and is concerned with bargaining over substantive issues of importance to him. Once these issues are settled it quickly and finally reaches the resolution/surrender stage when the Bomber is arrested..

\section{The Use of Active Listening}

In terms of the analysis of the use of active listening, as already mentioned, its use by negotiators is a basic feature of the Expressive negotiation approach, an approach which emphasizes the importance of the nature and quality of interpersonal relationships formed in attempting to resolve a crisis (although it is of use in the other stages of a crisis negotiation since the relationship has to be maintained). The interactional linguistic choices made by a negotiator, in response to the language choices of the perpetrator, are therefore obviously of prime importance in this. What follows, in line with Hammer and Rogan's interactive approach to the analysis of negotiation dynamics, is an examination of the unfolding exchange between O'Reilly and the Bomber, and an identification of the instances where O'Reilly draws upon 
active listening skills to establish rapport with the subject and defuses a potentially volatile situation..

In active listening for crisis incidents, the usage of ' $\mathrm{I}$ ' messages is usually discussed in terms of a negotiator expressing his feelings about the perpetrator's actions so that he seems like a real person to the perpetrator, as in I feel that .. or I get worried when ... etc. In the examples given below, O'Reilly does in fact use the referential first person singular, but not to express his feelings about what the Bomber says or asserts. What is interesting interactionally is his usage of the range of referential forms available to him, the reasons why, and the effect these choices have on the exchange as it develops. O'Reilly commences the negotiation with an identificational ' $\mathrm{I}$ ' message, where he states who he is and his status - note though that he uses a first name vocative, not his last name or his police rank, and he uses a first name vocative for the Bomber (O’Reilly only gives his full name when the Bomber is finally arrested, in response to a request for it by the Bomber). O'Reilly then immediately uses the referential first person plural ' $w e$ ', thus identifying himself with the other interactants in the situation (the police tactical and bomb disposal teams, the Saracen armored vehicle, the townspeople). This establishes his authority and position in the situation:

\section{Bomber: Hello?}

O’Reilly: Hello, “B”.

Bomber: Who's this?

O’Reilly: $\quad$ Yes, my name's $\underline{\text { John, }}$ “B”. I'm a police negotiator.

Bomber: Oh, yeah.

O'Reilly: $\quad$ We know you've been going into town with a bomb and there's a lot of people very worried about that. O.K. That's why we're here, because we know you've got guns and we know_that you've got a bomb.

In response and to justify himself, the Bomber immediately personalizes through his use of first person singular ' $I$ ', so in order to establish initial rapport and to produce a distancing effect from these 'others', O’Reilly briefly switches to a usage of first person singular " $I$ " and uses the non-assertive "no-one" to generalize the claim about people not wanting to attack. There is also a first usage, for distancing purposes also, of his referral to these previously identified 'others', through the third person plural and verbal contraction “they're”.

Bomber: $\quad$ Well that's only if I was attacked.

O'Reilly: $\quad$ I understand what you mean, but no-one wanted to attack you, no-one wants to go near you, they're frightened, very worried about the bomb. You can understand that, can't you?

Bomber: $\quad$ Yes, but it's absolute safe when I've got it. 
O’Reilly:

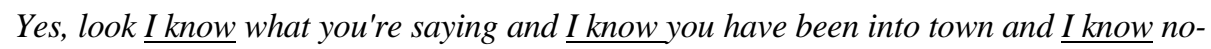
one's been injured.

The continuation and multiple use of ' $I$ know' in response to the Bomber's direct and abrupt statement on safety are also instances of the rapport-building ' $I$ ' messages. O’Reilly still however must ensure that the Bomber still sees him, at some level, as a figure associated with the police by the brief use of the inclusive first person plural "we", but he quickly switches again into the use of the more intimate first person singular to convey the fact that the Bomber will be dealing with him, and not those 'others', whom he also refers to as 'police' and later as 'the police'. These choices are deliberate and necessary for the Bomber to be able to start aligning himself with O’Reilly, to feel some sense of rapport (O’Reilly 2003). This attempt at relationship building is further reinforced through the use of the third person plural pronominal "they" for the tactical team and the noun phrase "the people in town" in the following:

Bomber: $\quad$ No-one will be either unless you decide to declare war on me.

O'Reilly: $\quad$ No, we don't want to declare war on you, not at all, not at all, but I do need you to take off the bomb and to leave the guns on the roadway there.

Bomber: $\quad$ Well certainly I'm going to keep my weapons, I've had them for most of my life.

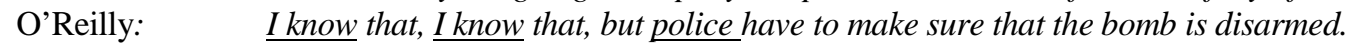

Bomber: $\quad$ Yes.

O'Reilly: $\quad$ And they can't let you go with the weapons, they are going to have to take the weapons from you now. You are under arrest, O.K.?

Bomber: $\quad$ Now listen, this is absolutely bloody ridiculous.

O'Reilly: I $\quad$ know from your perspective it may seem ridiculous, but the people in town are very worried about it and the police are obligated to act, as you can understand.

The interactional sub-text here is that 'they' can do these things, that these “others” are frightened and worried, but "I” am here to help you [the Bomber] get out of this predicament (to solve the problem). In doing this O’Reilly removes himself from an association with the potential actions of the 'others', and starts to set himself up as the 'rescuer'. He is in a sense identifying with the plight of the Bomber and will work with him to help him save himself. This process of identification can of course cause problems for a negotiator in dealing with tactical team members, who can sometimes view this identification process as “coddling, sympathetic," and as "siding with the bad guy” (Cambria 2002: 339).

The identification process with the Bomber is reinforced very quickly by O’Reilly's assurance:

O'Reilly: $\quad$ Now there's no problem, you're safe if you stay where you are, but you won't be safe if you leave that spot. 
This facilitates the next series of exchanges in the negotiation, where O'Reilly starts to firmly take on the role of the 'rescuer', but where the Bomber's developing realization that he is in a predicament, that he is boxed in by the police leads to some agitation. At this point O’Reilly cuts him off with an imperative, but continues to refer to 'the police' and 'them' in order to maintain the sense of separation and the idea that it is these “others' who are constraining the Bomber, not O'Reilly. His reference to the 'Saracen' adds further to the sense of the 'otherness' for the Bomber, and is a deliberate choice of words by O'Reilly because he knows that the Bomber would be impressed by the machine and the tactics used (O’Reilly 2004).

\footnotetext{
Bomber: $\quad$ The police -- -

O'Reilly: $\quad \quad \quad \quad$ Now just listen to me for one second please, "B". The police can't let you get near them because of that bomb.

Bomber: $\quad$ I don't intend to get near them, dear or dear, I'll go back home.

O'Reilly: $\quad$ No, you can't go home "B".

Bomber: $\quad$ What are you gunna do, shoot me in the back?

O'Reilly: $\quad Y o u$ can't leave that area, there's police all around you, there's police back down the road towards your house. If you look down the road you'll see a saracen.

Bomber: $\quad$ Down the, which way?

O’Reilly: $\quad$ The way you've come, you can't go back that way.
}

The Bomber confirms this perception of being constrained by the 'others' and signals his reaction and the beginnings of a change in attitude by stating

$\begin{array}{ll}\text { Bomber: } & \text { This is amazing. } \\ \text { O’Reilly: } & \text { O.K. }\end{array}$

and his next comment reveals this change in tenor when he asks O’Reilly about his planned actions, not the police's, and in doing so assigns him the agency in the situation:

Bomber: Rightio, well what are you going to do?

O’Reilly signals and accepts this tenor change by multiple uses of first person singular, but notice that he does not actually answer the rhetorical thrust of this question by stating what he will do, but instead he turns it around into what the Bomber needs to do for him, the 'rescuer/negotiator'. Of interest also is the lack of overt agency in about what is going to happen - neither the police nor O’Reilly are identified as the doers of this action, things just 'happen'.

O’Reilly: $\quad$ Well I need you to take off your overalls and take off the bomb and put it down on the road.

Bomber: $\quad$ Then what do you intend to do?

O'Reilly: $\quad$ Well I need you to take the guns out of your pockets and the holster and put them on the road as well and I need you to take your overalls off and just walk back towards the police, down in the direction of the saracen, but you can't walk down that way until the 
bomb, the guns, your overalls are on the road. We need to know that you've got no weapons on you, O.K. And what's going to happen then, you'll be taken to the police station and you'll just be interviewed about firearms offences. Now the offences aren't as serious as you might think, because I know that you haven't harmed anyone.

This is a very important interactional stage for the Bomber and O’Reilly, because they are now "in this together" (Cambria 2002: 339), and it represents the start of the process of disarming the bomb and the removal of the weapons. After some brief discussion of the process of leaving Australia and securing his property (and O’Reilly is fully aware of its importance to the Bomber), O'Reilly confirms his 'rescuer' role and the trust it implies by then stating what he will do after the compliance:

O'Reilly: $\quad$ Now what I'm going to do is, I'll get you out of here safely and this can all be discussed in detail later on.

At this point the Bomber knows that he has been isolated and constrained. This is, in essence, the critical turning point where he capitulates and allocates decisionmaking and advising power to O’Reilly. The Bomber has been boxed in, isolated both physically and psychologically, but has found an 'out' to his predicament in the person of the negotiator, with whom he has formed a relationship. O’Reilly can now move through to the adaptations/negotiation phase and assist the Bomber to get out of his predicament by going through the process of laying out the bomb, weapons and ammunition in a fashion which is acceptable to the safety concerns of the bomb and tactical squads.

This allocation of decision-making power to O'Reilly can be seen in the following extract a few more minutes into the negotiation, where O’Reilly has in effect become the 'rescuer' of the bomber, though not totally, because the Bomber still continues to raise substantive issues to do with his property. The negotiation is "not over until its over" (340), but it has reached the point where what has been referred to as "the surrender ritual” can begin, where the process of leading the perpetrator out of the mess he/she is in takes on clear interactional steps, steps which in this incident are largely concerned with the substantive issues of concern to the Bomber (335). O’Reilly intuited this when he stated: "When the meaningful conversation started and he asked me a question about the future, I felt very confident that it would resolve peacefully” (2003).

O'Reilly: $\quad \quad \quad$ You have to stay in the center of the roadway.

Bomber: Well um, oh dear.

O’Reilly: $\quad$ I'll talk to you through this. 

Bomber:
Yes.
O’Reilly:
And get you out. You will be safe if you do as I ask and - - -
Bomber:
I mean look at the way you've got it, you've fenced the area in, no doubt you're a bad lot of bastards.
O’Reilly: $\quad$ Well it's only because people are so concerned about that bomb, that's the problem " $B$ ”, so - - -
Bomber: $\quad$ Yeah, well I shouldn't have went out. Um, well I mean, will this interfere with me selling my land?
O’Reilly: $\quad$ No, no it won't interfere with you selling your land at all.
Bomber: $\quad$ Are you sure of that?
O'Reilly: $\quad$ Positive, positive.
Bomber: $\quad$ And will it interfere with me getting out of the country?
O'Reilly: $\quad$ No, I don't think so at all. Once this matter is sorted out you can do, you are free to do whatever you want.

O'Reilly does use other aspects of the active listening skill in order to build rapport. One of these is mirroring, where he repeats the last words/ phrases or main idea provided by the Bomber to mirror back to him the ideas or feelings that he has stated, to let him know that what is being stated is being listened to (though not necessarily accepted), that he is being understood. We have various instances, such as where O’Reilly is negating and reassuring regarding the Bomber's fear of attack, or the perception of a threat of declaration of war by police,

Bomber: $\quad$ Well that's only if I was attacked.

O'Reilly: $\quad$ I understand what you mean, but no-one wanted to attack you, no-one wants to go near you, they're frightened, very worried about the bomb. You can understand that, can't you?

where O'Reilly is mirroring in order to negate and reassure regarding the Bomber's conditional statement about a declaration of war by police,

Bomber: $\quad$ No-one will be either unless you decide to declare war on me.

O'Reilly: $\quad$ No, we don't want to declare war on you, not at all, not at all, but I do need you to take off the bomb and to leave the guns on the roadway there.

and when O'Reilly is mirroring in order to reflect the Bomber's feelings/emotions about the fact that the he is under arrest and cannot keep his weapons:

Bomber: $\quad$ Now listen, this is absolutely bloody ridiculous.

O'Reilly: $\quad$ I know from your perspective it may seem ridiculous, but the people in town are very worried about it and the police are obligated to act, as you can understand.

Another active listening skill which O’Reilly uses minimally is paraphrasing, where he uses a paraphrase of what the Bomber has said to him either immediately before or earlier in the exchange. For example, we have a comment on the bomb’s safety:

Bomber: $\quad \quad \quad \quad$ Yes, but it's absolute safe when I've got it.

O’Reilly: $\quad$ Yes, look I know what you're saying and I know you have been into town and I know no- 
What also stands out in this exchange between the Bomber and O'Reilly is the use of an interactional technique which has not really been covered in the literature on active listening in crisis situations. That is the consistent usage, throughout the entire negotiation, of what could be referred to as reflective empathizers, which do not reflect back the propositional content of the Bomber's utterances through repetition or synonymizing (which is what mirroring is basically described as doing), but ellipses the meanings expressed and works to maintain the interactional exchange at a discoursal level. These reflective empathizers are clearly being used for maintaining the interactional flow for rapport building purposes (by acknowledging the illocutionary force of previously given messages). They can be seen in the following examples in the phase of the negotiation being analyzed:

Bomber: $\quad$ Well that's only if I was attacked.

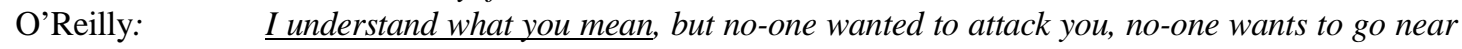
you, they're frightened, very worried about the bomb. You can understand that, can't you?

Bomber: $\quad \quad \quad$ Yes, but it's absolute safe when I've got it.

O'Reilly: $\quad Y e s$, look I know what you're saying and I know you have been into town and I know noone's been injured.

There is also an ellipsis of the knowledge that the Bomber loves his weapons and has had them most of his life,

Bomber: $\quad$ Well certainly I'm going to keep my weapons, I've had them for most of my life.

O'Reilly: $\quad$ I know that, I know that, but police have to make sure that the bomb is disarmed.

followed by an expressed empathy with what the Bomber is going through:

Bomber: $\quad$ Now listen, this is absolutely bloody ridiculous.

O'Reilly: $\quad$ I know from your perspective it may seem ridiculous, but the people in town are very worried about it and the police are obligated to act, as you can understand.

Other empathic and rapport-building features are the use of tag questions and eliciting statements which are used to draw out some appreciation or acknowledgment of other people's feelings and positions. These are used to draw out some kind of verbal or emotive response in the Bomber, as in:

\footnotetext{
Bomber: $\quad$ Well that's only if I was attacked.

O'Reilly: $\quad$ I understand what you mean, but no-one wanted to attack you, no-one wants to go near you, they're frightened, very worried about the bomb. You can understand that, can't you?

Bomber: $\quad$ Yes.

O'Reilly: $\quad \overline{A n d}$ they can't let you go with the weapons, they are going to have to take the weapons from you now. You are under arrest, O.K.?

Bomber: $\quad$ Now listen, this is absolutely bloody ridiculous.
} 
O'Reilly: I know from your perspective it may seem ridiculous, but the people in town are very worried about it and the police are obligated to act, as you can understand.

Once this rapport has been established, there is a lengthy exchange where O’Reilly and the Bomber discuss his possessions, each item in the arsenal on his body and how it should be removed and laid out. The Bomber in the end has completely removed all his clothes, the bomb has been removed, defused, and its components laid out on the ground in a neat row. The weapons and the ammunition have also been removed and rendered inactive, and all personal items have been laid out on the ground in a neat fashion. The Bomber in effect has basically vested his faith in the believability of the negotiator and he in turn receives honestly given assurances re his treatment with dignity as he disrobes, the legal processes involved in his charges, and the steps he can take regarding the sale of his land and eventual departure from Australia.

A final comment can also be made on other active listening skills that were available to O'Reilly, but seem to be minimally used in the initial stages analysed here: open-ended questions, minimal encouragements, and effective pauses. The only open-ended question which occurred was close to the point where the 'surrender ritual' began. This involves the Bomber's response to O’Reilly's lengthy statement of what the Bomber should do for him. At that point he asks an open-ended question which requires the bomber to provide the information on the substantive issue of concern, the property:

O’Reilly:

Now the offences aren't as serious as you might think, because I know that you haven't harmed anyone.

Bomber Well this means I've finished with this bloody country then.

O'Reilly: $\quad$ How do you mean?

Bomber Well what about my property and everything?

In terms of minimal encouragements, an individual instance of this is where O’Reilly acknowledges the Bomber's amazement at the ways that he has been boxed in and the appearance of a Saracen. The function of this utterance, as a minimal encourager, is to elicit further comment by the Bomber, a comment which actually signals the pivotal point where he asks O’Reilly what he is going to do, and where the processes leading towards surrender can commence:

Bomber: $\quad$ This is amazing.

O’Reilly: $\quad$ O.K.

Bomber: $\quad$ Rightio, well what are you going to do? 
In this stage of the negotiation there are no instances of effective pauses where the negotiator uses silence to draw out the Bomber. Perhaps this lack of usage and the minimal usage of encouragers and open-ended questions is because the negotiator has no need to use these information-gathering methods since he is fully aware of the issues through the background intelligence obtained. Therefore, what he uses mostly are the active listening techniques which focus more on rapport-building than on information gathering.

\section{CONCLUSION}

The linguistic choices made by O'Reilly in his interaction with the Bomber, and the effective use of active listening techniques to establish an initial rapport with him in the crisis/defusing stage have been instrumental in the successful resolution rather than escalation, of this crisis. O'Reilly was able to effect a disassociation from the 'police' and to build rapport as the interaction developed via his adaptive use of personal referential pronominals. He was also able to give the Bomber the impression that he was empathetic through a judicious use of reflective empathizers, which was supported by other active listening techniques such as mirroring, and paraphrasing. As empathy developed, and the Bomber began to see a way out of his predicament, O’Reilly was able to bring in the "voice of reason" to start to move the interaction towards the resolution/surrender phase (O’Reilly 2003). Further, the effective use of negotiation skills in the accepting, caring and patient attitude which McMains \& Mullins (2001: 69) recommend for all stages of a crisis contributed to saving the Bomber's life, especially given the fact that the negotiation and tactical teams fully expected he would be shot, and that they would have to defuse the bomb.

This analysis suggests areas for further interactional study of this kind of incident. One important area would be an analysis of how an awareness and use of contextual knowledge in a negotiation can influence a negotiator's language choices as he is using active listening. This would provide another perspective on the ways that interactions in these situations can unfold. This would be appropriate whether the contextual information was obtained in advance or as the interaction proceeds via the usual note-taking and team data feeds to the negotiator as he speaks. For example, in the incident analysed here, O’Reilly says at one point,

O'Reilly: $\quad$ I understand what you mean, but no-one wanted to attack you, no-one wants to go near you, they're frightened, very worried about the bomb. You can understand that, can't you? 
These kinds of statements include background content knowledge and attempt to convey understanding and empathy. They did not arise out of pre-prepared or stock phrases, but are responses which reflect O'Reilly's understandings of the Bomber's personality traits and negative feelings towards others (see Table One). O’Reilly is aware that the Bomber is carrying the weapons and bomb for fear of attack, and he knows that comments about the fearfulness of people would feed into the Bomber's elitist and disdainful attitudes to the general public. It is a clear recognition and appreciation of the bomber's insecurities and his need to be in control. O’Reilly also deliberately referred to the Saracen armored vehicle, because he knew of the Bomber's strong empathy with and respect for machines (2003).

Obviously, taking an interactional view of negotiation processes is a very complex undertaking, but it clearly has ramifications for the training of police negotiators. It would be especially useful in the development of interactive CD-ROM training programs, where networks of potential language choices could be built into software. These could be based around the kinds of speech roles taken up by the interlocutors, and the patterns of interaction based on descriptors such as statementacknowledgement, question-answer, command-compliance, offer-acceptance etc. These kinds of descriptors could also be used for move analyses to clarify the genres that are being used in different crisis negotiation contexts.

One other interesting area would be an intonational analysis of vocal recordings of these kinds of interactions, especially in the move from the public megaphone to the more 'intimate' police phone. This could be correlated with the functional moves occurring as an interaction unfolds. On this latter point, the importance of a contextualised analysis of the Bomber text can be further demonstrated by a comment made by this writer to O’Reilly. The comment was that a certain aspirated or stressed quality to the negotiator's voice could be heard in the initial stages, which, it was suggested, might be the result of the emotional excitation involved in this particular case. O’Reilly disagreed - it turned out that the Bomber had suddenly appeared over the small rise in the dirt road on his motorised bike, and that he had to sprint 100 metres through the forest to the communications centre. Obviously for the analyst this kind of information relating to the physical context constitutes key information that could affect an interactional interpretation, and as suggested, further demonstrates that contextual variables should be an important component of an interactional analysis of a crisis negotiation, because the choices made are a result of the interaction of 
language with context. On this point it would seem fitting to end on a quote from

O'Reilly about the dynamic interactional nature of crisis negotiation:

In my opinion, one of the most important skills for a negotiator is flexibility. The only thing you can really plan is an opening statement. Where you go from there is entirely dependant on the response of the subject. Immediately prior to this incident, the only thing I had planned was the opening statement (2003).

\section{REFERENCES}

Active Listening: International Online Training Program On Intractable Conflict. 1998. University of Colorado: Conflict Research Consortium. Available at the following website: www.colorado.edu/conflict/peace/treatment/activel.htm

Cambria, J. and R. J. DeFilippo, R. J. Louden, H. McGowan. 2002. Negotiation Under Extreme Pressure. Negotiation Journal 18 (4): 331-343.

Crisis Negotiation. 2004. Bureau of Criminal Investigation: Virginia State Police. Available at the following website: www.vsp.state.va.us/bci_gid_crisis.htm

Emery, G. 2002. CD-ROM simulations gain foothold. Washington Technology February $4^{\text {th }}, 16$ (21). Available at the following website: www.washingtontechology.com/news/16_21/federal/17772-1/html

Franks, L. 1996. Don't Shoot: In the FBI, patience comes first. Annals of Law Enforcement. The New Yorker 26-31.

Fuselier, D. 1999. Placing the Stockholm Syndrome in Perspective. FBI Law Enforcement Bulletin July, 68 (7): 22-25.

Halliday, M.A.K. 1994. An Introduction to Functional Grammar. 2nd ed. London: Edward Arnold.

Lanceley, F. J. 1999. On-Scene Guide for Crisis Negotiators. Boca Raton: CRC Press.

Landsberger, J. 2003. Study Guides and Strategies: Active Listening. The University of

St. Thomas (UST), St. Paul, Minnesota. http://www.iss.stthomas.edu/studyguides/listening.htm

Listening Skills: A powerful key to successful negotiating. 2000. The Apocalypse Suicide Page. HealthyPlace.com, Inc. Available at the following website: www.healthyplace.com/Communities/Depression/wilkerson/

McMains, M. J. and W. C. Mullins. 2001. 2nd Ed. Crisis Negotiations: Managing 
critical incidents and hostage situations in law enforcement and corrections. Cincinnati: Anderson Pub. Co.

National Council of Negotiation Associations (NCNA) 2001. Recommended Negotiation Guidelines and Policies. Available at the following website: www.wshna.org/NCNA_guidelines.htm

Noesner, G. W. 1999. Negotiation Concepts for Commanders. FBI Law Enforcement Bulletin January, 68 (1): 6-14.

Noesner, G. W. and Webster, M. 1997. Crisis Intervention: Using Active Listening Skills in Negotiations. FBI Law Enforcement Bulletin. August, 66 (8), A pdf file available at the following website: www.fbi.gov/publications/leb/1997/aug974.htm

O’Reilly, J. 2003. Personal Correspondence. Sydney, Australia.

Pickering, M. 1986. "Communication" Explorations: A Journal of Research of the University of Maine, Fall, 3 (1): 16-19. In the following website: www.hci.com.au/hcisite2/docotools/course/write1.htm

Potter, B. 1995. From Conflict To Cooperation: How To Mediate A Dispute. Berkeley, CA: Ronin Publishing,.

Psathas, G. 1995. Conversation Analysis: The study of talk-in-interaction. Qualitative Research Methods Series, No. 35. Sage Publications.

Rogan, R. G. and M. R. Hammer, C. Van Zandt. 1997. Dynamic Processes of Crisis Negotiation. Westport, Connecticut: Praeger.

Romano, S. J. 1998. Third Party Intermediaries for Crisis Negotiations. FBI Law Enforcement Bulletin October, 67 (10): 20-24.

Romano, S. J. 2002. Communication Survival Skills for Managers. FBI Law Enforcement Bulletin September, 71 (9): 14-16.

Rosenthal, C. 2003. Active listening skills. Utah State University Academic Resource Center Idea Sheets: Active listening skills. Available at the following website: www.usu.edu/arc/idea_sheets/active.htm

Schlossberg, H. 1979. Hostage Negotiations School. Austin, TX: Texas Department of Public Safety.

Will Interactive 2004. The Incident. CD-ROM. Available at the following websites: www.willinteractive.com \& www.wshna.org/training.htm 
Wind, B. 1995. A Guide to Crisis Negotiations. FBI Law Enforcement Bulletin October, 64 (10): 7-12. 